\title{
Rendimento e composição químico-bromatológica de fenos triturados de gramíneas tropicais $^{1}$
}

\section{Emerson Moreira de Aguiar², Guilherme Ferreira da Costa Lima ${ }^{3}$, Mércia Virgínia Ferreira dos Santos ${ }^{4}$, Francisco Fernando Ramos de Carvalho ${ }^{4}$, Adriana Guim ${ }^{4}$, Henrique Rocha de Medeiros $^{5}$, Aurinês Queiroz Borges ${ }^{6}$}

${ }^{1}$ Parte da tese apresentada pelo primeiro autor ao Programa de Doutorado Integrado em Zootecnia da UFRPE. Projeto financiado pela FINEP/CONECIT - RN.

2 Departamento de Agropecuária - UFRN - Natal-RN.

3 EMBRAPA/EMPARN - Natal-RN.

${ }^{4} D Z / U F R P E$ - Recife-PE

5 Bolsista CNPq/EMPARN - Natal-RN.

${ }^{6}$ Graduação em Zootecnia - UFRN. Bolsista CNPq - Natal-RN.

RESUMO - A pesquisa foi conduzida objetivando avaliar o rendimento, a composição químico-bromatológica e as perdas de fenos triturados de milheto, sorgo sudanense, capim-elefante e sorgos forrageiros (SF-25 e IPA-467-4-2). Os materiais foram colhidos quando atingiram $30 \%$ de inflorescências, com exceção do capim-elefante, colhido aos 60 dias. Utilizou-se delineamento de blocos completos casualizados, com cinco tratamentos e quatro repetições. Houve diferenças significativas, com maiores produções de fenopara os sorgos IPA-467-4-2 (10,85 t/ha/corte) e SF-25 (10,65 t/ha/corte), que foram superiores ao capim-elefante, sorgo sudanense e milheto, com, respectivamente, 6,94; 6,69 e 4,93 t/ha/corte. Os percentuais de perdas na fenação não diferiram entre os tratamentos, com níveis variando de 17,33 a 20,17\%. Os fenos de milheto e sorgo sudanense tiveram as maiores concentrações de PB (10,56 e 8,80\%), superiores às do capim-elefante $(6,76 \%)$ e dos sorgos SF-25 (5,62\%) e IPA-467-4-2 (5,50\%). Os valores de FDN foram, na maioria, superiores a 70,0\%. As menores concentrações de NIDN foram observadas nos cultivares de sorgo $(0,42$ e $0,40 \%$ da MS). As concentrações de NIDA variaram de 0,06 a $0,30 \%$ na MS. As maiores concentrações de lignina (\%MS) dos fenos foram obtidas no milheto (6,52\%) e no sorgo IPA-467-4-2 (6,17\%). As concentrações de nutrientes digestíveis totais estimadas $\left(\mathrm{NDT}_{\mathrm{e}}\right)$ dos fenos diferiram significativamente, com o maior valor para o sorgo sudanense $(53,35 \%)$. Os fenos triturados das gramíneas tropicais avaliadas apresentaram rendimentos elevados e composição químico-bromatológica dentro dos padrões mínimos recomendáveis para nutrição de ruminantes.

Palavras-chave: agricultura familiar, fenação, Pennisetum americanum, Pennisetum purpureum, Sorghum bicolor, Sorghum sudanense

\section{Yield and chemical composition of chopped tropical grass hays}

\begin{abstract}
The research was carried out to evaluate yield, chemical composition and losses of chopped tropical grass hays with the following forages: pearl millet (Pennisetum americanum), sudangrass (Sorghum sudanense), elephantgrass (Pennisetum purpureum) and two cultivars of forage sorghum (SF-25 and IPA-467-4-2) (Sorghum bicolor). The materials were harvested at 30\% flowering, except for elephantgrass (60 days). The experiment was conducted according to a complete randomized block design, with five treatments and four replications. There were significant differences among hay productions with sorghum cultivars IPA-467-4-2 and SF-25 reaching the highest yields (10.85 and 10.65 t/ha/cut). Production of elephantgrass, sudangrass and pearl millet hays were respectively of $6.94,6.69$, and $4.93 \mathrm{t} / \mathrm{ha} / \mathrm{cut}$. Percentage of hay losses were not different among all treatments and varied from 17.33 to $20.17 \%$. Pearl millet and sudangrass hays had the highest CP concentrations (10.56 and $8.80 \%$ ), which were superior to elephantgrass $(6.76 \%)$ and sorghum cultivars $(5.62$ and $5.50 \%)$. Most of the NDF values were superior to $70.0 \%$. Sorghum cultivars exhibited the lowest NDIN concentration $(0.42$ and $0.40 \%$ of DM). The ADIN concentration ranged from 0.06 to $0.30 \%$ of DM. The highest lignin (\%DM) concentration was observed for pearl millet (6.52\%) and sorghum IPA-467-4-2 (6.17\%) hays. Estimated TDN of the hays showed significant differences and sudangrass reached the highest value (53.35\%). Production of chopped tropical grass hays showed high yields and chemical composition according to the minimum standards for ruminant nutrition.
\end{abstract}

Key Words: familiar agriculture, haymaking, Pennisetum americanum, Pennisetum purpureum, Sorghum bicolor, Sorghum sudanense 


\section{Introdução}

A exploração de ruminantes com base na utilização intensiva de pastagens torna a atividade mais econômica, pois a colheita é realizada pelo próprio animal (Silva \& Corsi, 2003). Segundo Santos et al. (2003), pastagens tropicais produzem forragem adequadamente por 180 a 200 dias no ano. No entanto, no período restante, o produtor deve buscar alternativas para suprir a baixa disponibilidade de forragem, o que dificulta a viabilidade econômica da atividade pecuária e impede que o potencial de produção das plantas forrageiras seja aproveitado ao longo de todo o ano. Esse fato determina uma crescente busca por processos de conservação de forragem como forma de garantir o fornecimento constante de alimentos aos animais.

Desse modo, o processo de fenação constitui uma das alternativas ao problema da sazonalidade das plantas forrageiras, permitindo que o excedente produzido em pastagens ou em áreas exclusivas de cultivo possa ser armazenado e empregado na alimentação dos animais em épocas de escassez.

Segundo Barbera, citado por Ben Salem \& Nefzaoui (2002), o futuro das regiões áridas e semi-áridas do mundo depende do desenvolvimento de sistemas agrícolas sustentáveis e do plantio de culturas adaptadas. Entre algumas espécies que se incluem nesse contexto, destacam-se o milheto (Pennisetum americanum (L.) Leeke), o sorgo sudanense (Sorghum sudanense (Piper) Stapf.) e o sorgo forrageiro (Sorghum bicolor (L.) Moench.). Ocapim-elefante (Pennisetum purpureum Schum.), embora não seja adaptado à escassez de umidade, é uma forrageira importante para o semi-árido, haja vista a tradição cultural do cultivo de capineiras de elevada produtividade e qualidade forrageira. Confirmando essa tradição, Nobre et al. (1998) encontraram essa espécie em 93,4\% dos estabelecimentos que exploram a pecuária leiteira no Rio Grande do Norte.

Entretanto, essas capineiras, em geral, são manejadas inadequadamente no período da estação chuvosa, na qual concentram aproximadamente $80 \%$ de suas produções. Da mesma forma, as rebrotas dos campos de sorgos forrageiros cultivados para ensilagem são desperdiçadas quando poderiam ser utilizadas, por exemplo, para o processo de fenação.

As culturas do milheto, o sorgo sudanense, o capimelefante e os sorgos forrageiros (SF-25 e IPA-467-4-2) não apresentam as características tradicionais das forrageiras típicas para fenação, em virtude da presença de colmos grossos e da baixa relação folha/colmo, que não proporcionam dessecação uniforme dessas frações. A trituração dessas forrageiras de caules eretos facilita a desidratação podendo representar mais uma alternativa viável para reverter o quadro de escassez de volumosos no período seco do ano, particularmente para as unidades da agricultura familiar do semi-árido (Lima \& Maciel, 1996).

O objetivo nesta pesquisa foi avaliar o rendimento, a composição bromatológica e as perdas de gramíneas forrageiras tropicais na produção de fenos triturados.

\section{Material e Métodos}

O cultivo das gramíneas foi realizado na Estação Experimental "Felipe Camarão", situada em São Gonçalo do Amarante - RN, e a preparação dos fenos triturados foi feita em secadores solares e o armazenamento no Centro Profissionalizante de Produção Animal de Seridó, Município de Cruzeta - RN, ambos pertencentes à Empresa de Pesquisa Agropecuária do Rio Grande do Norte S/A - EMPARN.

O solo da área experimental foi classificado como aluvial de textura franco-arenosa, com a seguinte granulometria: areia $57 \%$; silte $26 \%$ e argila $17 \%$. A área era situada à margem do rio Potengi e apresentou níveis elevados de fertilidade e acidez moderada, com o seguinte resultado da análise do solo: $\mathrm{pH} 5,90, \mathrm{P}=34 \mathrm{mg} / \mathrm{kg}$ (Mehlich-1), $\mathrm{K}=275 \mathrm{mg} / \mathrm{kg}, \mathrm{Na}=29 \mathrm{mg} / \mathrm{kg} \mathrm{Ca}=4,70 \mathrm{cmol}_{\mathrm{c}} / \mathrm{kg}$, $\mathrm{Mg}=1,91 \mathrm{cmol}_{\mathrm{c}} / \mathrm{kg}, \mathrm{Al}=0,00 \mathrm{cmol}_{\mathrm{c}} / \mathrm{kg}, \mathrm{H}=3,63 \mathrm{cmol}_{\mathrm{c}} / \mathrm{kg}$, $\mathrm{MO}=22,2 \mathrm{~g} / \mathrm{kg}, \mathrm{S}=14,91 \mathrm{cmol}_{\mathrm{c}} / \mathrm{kg}, \mathrm{CTC}=18,54 \mathrm{cmol}_{\mathrm{c}} / \mathrm{kg}$ e $\mathrm{V}=80,42 \%$ na camada $0-20 \mathrm{~cm}$ de profundidade.

As precipitações pluviométricas mensais registradas na Estação Experimental no período do plantio à colheita das culturas foram de 223,5; 101,5 e 198,4 mm nos meses de junho, julho e agosto de 2002, respectivamente.

O processo de trituração e fenação foi realizado nos meses de julho a setembro de 2002 , período em que a temperatura média mínima foi de $20,8^{\circ} \mathrm{C}$ e a máxima de $32,4^{\circ} \mathrm{C}$, a umidade média do ar variou de 54,0 a $66,0 \%$ e a média de insolação foi de 272,8 horas e décimos. A precipitação pluvial total para os três meses foi de apenas $25,5 \mathrm{~mm}$ (INMET, 2002).

Os tratamentos experimentais consistiram de fenos de diferentes espécies forrageiras, triturados e desidratados em secadores solares. Essas espécies foram distribuídas em um delineamento experimental em blocos completos casualizados, com cinco tratamentos e quatro repetições: milheto cv. IPA-Bulk-1(Pennisetum americanum(L.)Leeke), sorgo sudanense cv. Sudan-4202 (Sorghum sudanense (Piper) Stapf.), capim-elefante cv. Cameroon (Pennisetum purpureum Schum.), sorgo forrageiro cv. IPA-SF-25 e sorgo forrageiro cv. IPA-467-4-2, ambos Sorghum bicolor(L.) Moench. 
A área foi dividida em quatro blocos e cada parcela experimental foi constituída de uma área total de $252,0 \mathrm{~m}^{2}$ $(21,0 \times 12,0 \mathrm{~m})$, com espaçamento entre linhas de $0,70 \mathrm{~m}$, totalizando 30 linhas em cada parcela.

Para a produção dos fenos, foi implantada uma área total de $5.040 \mathrm{~m}^{2}$. O solo foi preparado e adubado com $7.000 \mathrm{~kg}$ de esterco bovino, $30 \mathrm{~kg} \mathrm{~N} / \mathrm{ha} \mathrm{e} 40 \mathrm{~kg} \mathrm{P}_{2} \mathrm{O}_{5} / \mathrm{ha} \mathrm{e}$ adubação de cobertura com $30 \mathrm{~kg} \mathrm{~N} / \mathrm{ha} \mathrm{e} 25 \mathrm{~kg} \mathrm{~K} 2 \mathrm{O} / \mathrm{ha}$, de acordo com a recomendação da análise de solo, o método de recomendações de adubação ( $2^{\mathrm{a}}$ aproximação) para o estado de Pernambuco (Cavalcanti et al., 1998), além dos tratos culturais.

Na Tabela 1 encontram-se as médias da composição químico-bromatológica das gramíneas que deram origem aos fenos. Após a retirada das bordaduras e das amostras para avaliação dos rendimentos de matéria verde, matéria seca e relação folha/caule, foi colhido o restante do material para preparação dos fenos (201,60 m²/parcela), mensurando-se a quantidade de feno obtida por espécie e por parcela, sendo posteriormente estimado o rendimento por hectare.

Para determinação do nível de perdas na produção dos fenos triturados, foi calculada a proporção entre a produção potencial e a produção real de feno obtida. O cálculo da produção potencial de feno foi realizado utilizando-se a produção de MS por hectare, acrescida da porcentagem de umidade remanescente no feno, obtida pela análise do teor de MS do mesmo.

O corte para preparação dos fenos foi feito quando $30 \%$ das plantas atingiram o florescimento pleno, com exceção do capim-elefante, que foi colhido aos 60 dias após o corte de uniformização. As plantas foram cortadas manualmente com cutelo pela manhã, antes das $9 \mathrm{~h}$, a uma altura de 10 a $15 \mathrm{~cm}$ do solo, com exceção do capimelefante, cujo corte foi rente ao solo. Após o corte, as plantas foram transportadas inteiras para Cruzeta-RN
$(220 \mathrm{~km})$, onde foram trituradas utilizando-se uma ensiladeira Menta-55 regulada para partículas de 2 a $3 \mathrm{~cm}$.

Em seguida, todo o material foi colocado em um secador solar cimentado (10,0 x 10,0 m), sendo espalhado em camadas de aproximadamente $10 \mathrm{~cm}$ e revolvido a cada duas horas para desidratação. Durante a preparação de todos os fenos, não ocorreram chuvas e não foi necessário amontoar o material ou cobrir com lona durante a noite.

$O$ ponto de feno foi definido utilizando-se o procedimento de determinação da MS da forragem com forno de microondas (Stapler, 2003), sendo alcançado em torno de dois dias para o milheto, sorgo sudanense e capim-elefante e de três dias para os sorgos forrageiros. O feno foi pesado e armazenado com teor de aproximadamente de $10 \%$ de umidade em sacos de polietileno sobre estrados de madeira afastados das paredes do armazém.

As amostras dos fenos triturados foram processadas em moinho tipo Willey com peneira de $1 \mathrm{~mm}$ para posteriores análises bromatológicas, realizadas no Laboratório de Nutrição Animal da Universidade Federal do Rio Grande do Norte. Foram determinados os teores de MS, cinzas, MO, PB, EE, LIG e CEL, segundo metodologia descrita por Silva \& Queiroz (2002), e os valores de FDN e FDA, conforme Van Soest et al. (1991). Os conteúdos de NIDN e NIDA foram determinados segundo Licitra et al.(1996). O teor de CT foi estimado pela equação: CT $(\%)=100-$ $[\mathrm{PB}(\%)+\mathrm{EE}(\%)+\operatorname{cinzas}(\%)]$ eos de CNF segundo Sniffen et al. (1992). Os valores de NDT estimados $\left(\mathrm{NDT}_{\mathrm{e}}\right)$ foram calculados de acordo com as equações formuladas pelo NRC (2001).

As análises de $\mathrm{Ca}, \mathrm{P}, \mathrm{K}, \mathrm{Mg}$ e $\mathrm{S}$ foram realizadas conforme Malavolta (1997).

Todos os procedimentos de análise estatística foram analisados peloprograma SAS (1995), aplicando-se o teste Tukey a $5 \%$ de probabilidade para compração de médias.

Tabela 1 - Composição química (\% da MS) das gramíneas forrageiras

Table 1 - Chemical composition (\% of DM) of forage grasses

\begin{tabular}{|c|c|c|c|c|c|}
\hline $\begin{array}{l}\text { Item (\% da MS) } \\
\text { Item (\% DM) }\end{array}$ & $\begin{array}{l}\text { Milheto Bulk-1 } \\
\text { Pearl millet Bulk-1 }\end{array}$ & $\begin{array}{c}\text { Sudanense S-4202 } \\
\text { Sudangrass }\end{array}$ & $\begin{array}{c}\text { Elefante Cameroon } \\
\text { Elephantgrass }\end{array}$ & $\begin{array}{l}\text { Sorgo SF-25 } \\
\text { Sorghum }\end{array}$ & $\begin{array}{c}\text { Sorgo IPA-467-4-2 } \\
\text { Sorghum }\end{array}$ \\
\hline $\operatorname{MS}(D M)$ & 22,28 & 21,45 & 23,33 & 25,42 & 26,51 \\
\hline $\mathrm{PB}(C P)$ & 11,89 & 9,44 & 7,59 & 7,28 & 6,63 \\
\hline $\mathrm{EE}$ & 1,74 & 2,43 & 1,86 & 1,89 & 1,84 \\
\hline FDN $(N D F)$ & 64,33 & 66,64 & 70,71 & 71,41 & 70,06 \\
\hline LIG & 6,37 & 4,45 & 4,52 & 5,62 & 5,83 \\
\hline Cinzas $(A s h)$ & 10,55 & 10,71 & 11,14 & 9,60 & 8,45 \\
\hline
\end{tabular}




\section{Resultados e Discussão}

Houve diferenças significativas $(\mathrm{P}<0,05)$ na produtividade dos fenos obtidos a partir das espécies forrageiras em avaliação (Tabela 2). As maiores produções de feno foram alcançadas com os cultivares de sorgo forrageiro IPA-4674-2 e SF-25, que não diferiram $(\mathrm{P}>0,05)$ e foram superiores aos demais tratamentos, com produções de 10.850 e $10.654 \mathrm{~kg} / \mathrm{ha} /$ corte, respectivamente. Esses valores refletem a alta produção de MS da espécie, o que corrobora os resultados descritos na literatura (Flaresso et al., 2000; Gontijo Neto etal., 2002; Neumann et al., 2002), com produções de híbridos de sorgo forrageiro em torno de 9,20 a $15,76 \mathrm{t} \mathrm{MS} / \mathrm{ha} /$ corte.

As produções de feno obtidas com o capim-elefante $(6.938 \mathrm{~kg} / \mathrm{ha} /$ corte $)$ e o sorgo sudanense $(6.686 \mathrm{~kg} / \mathrm{ha} /$ corte $)$ não diferiram entre si $(\mathrm{P}>0,05)$, sendo inferiores às registradas para os cultivares de sorgo e superiores às encontradas para o milheto (4.932 kg/ha/corte). Nobre (1987), em trabalho pioneiro na utilização de fenos triturados de capim-elefante no Rio Grande do Norte, obteve rendimentos de 7 a $12 \mathrm{t}$ de feno/ha. Lima et al. (2003) citam produções em torno de até $10 \mathrm{t} \mathrm{MS} / \mathrm{ha} /$ corte aos 60 dias para clones de capim-elefante produzidos pela Embrapa. A produção do milheto, no entanto, aproximou-se dos rendimentos por corte apontados por Geraldo et al. (2002) e Pinto et al. (2002), de 4,85 e 5,15 t MS/ha, respectivamente.

Essas produções podem ser consideradas expressivas para culturas forrageiras de sequeiro e com pequena utilização de fertilizantes, comparativamente às encontradas por empresas especializadas do Rio Grande do Norte utilizando capim-tifton sob irrigação e fertilização de até $400 \mathrm{~kg}$ $\mathrm{N} / \mathrm{ha}$, cujos rendimentos foram de 4,0 a 4,5 t feno/ha/corte e 20,0 a 30,0 t feno/ha/ano (Lima, 1998).
Os percentuais das perdas verificadas durante o processo da preparação dos cinco fenos triturados das gramíneas (Tabela 2) não diferiram $(\mathrm{P}>0,05)$, sendo obtidos níveis de 17,33 a $20,17 \%$. Esses valores estão de acordo com os descritos por Rotz \& Muck (1994), que citaram perdas de 15 a $30 \%$ nos processos de fenação, podendo situar-se entre 15 e $18 \%$ em condições de desidratação favoráveis. Vilela \& Vilaça (1998) relataram perdas de MS de $36 \%$ para feno de capim-elefante preparado em processo de desidratação a campo. Vários tipos de perdas podem ocorrer no recolhimento do feno, além daquelas consideradas inevitáveis, como respiração celular, fermentação, lixiviação, decomposição de compostos nitrogenados e oxidação de vitaminas (Reis et al., 2001). $\mathrm{Na}$ produção de fenos triturados, as perdas são ainda acrescidas pelos processos de trituração, distribuição para desidratação, revolvimento, carreamento pelo vento e recolhimento.

O conhecimento da composição bromatológica de um feno é fundamental para recomendação de sua utilização. Foram observadas algumas variações na composição bromatólogica do feno das diferentes espécies estudadas (Tabela 3). Segundo Haddad \& Domingues (2005), um feno de média a boa qualidade, independentemente da gramínea utilizada, deve apresentar composição média de: 7 a $13 \%$ de PB, 50 a $58 \%$ de NDT, 85 a $89 \%$ de MS, 35 a $44 \%$ de FDA, 75 a $81 \%$ de FDN e 6 a $10 \%$ de MM.

Os teores de MS variaram de 89,28 a $90,65 \%$, diferindo apenas para o sorgo forrageiro cv. IPA-467-4-2 em relação aos demais tratamentos. O teor de MS na preparação do feno é importante, pois determina a ocorrência ou não de processos fermentativos indesejáveis durante o armazenamento. Para os fenos triturados, em decorrência do pequeno tamanho das partículas ( 2 a $3 \mathrm{~cm}$ ) e do acondicionamento em sacos, é

Tabela 2 - Produção média de matéria verde (MV), MS e feno, relação matéria verde/feno (MV/feno) e índice de perdas na fenação das gramíneas forrageiras

Table 2 - Fresh matter yield (FM), DM yield, hay yield, fresh matter/hay ratio and haymaking losses of the forage grasses

\begin{tabular}{|c|c|c|c|c|c|c|}
\hline & $\begin{array}{l}\text { Milheto Bulk-1 } \\
\text { Pearl millet Bulk-1 }\end{array}$ & $\begin{array}{c}\text { Sudanense S-4202 } \\
\text { Sudangrass }\end{array}$ & $\begin{array}{c}\text { Elefante Cameroon } \\
\text { Elephantgrass }\end{array}$ & $\begin{array}{l}\text { Sorgo SF-25 } \\
\text { Sorghum }\end{array}$ & $\begin{array}{l}\text { Sorgo IPA-467-4-2 } \\
\text { Sorghum }\end{array}$ & $\mathrm{CV}(\%)$ \\
\hline $\begin{array}{l}\text { Produção de matéria } \\
\text { verde }(\mathrm{kg} / \mathrm{ha}) \\
\text { Fresh matter vield }(\mathrm{kg} / \mathrm{ha})\end{array}$ & $25.318 \mathrm{c}$ & $34.430 \mathrm{~b}$ & $33.863 b$ & $47.890 \mathrm{a}$ & $44.770 \mathrm{a}$ & 7,34 \\
\hline $\begin{array}{l}\text { Produção de MS }(\mathrm{kg} / \mathrm{ha}) \\
\text { DM yield }(\mathrm{kg} / \mathrm{ha})\end{array}$ & $5.646 \mathrm{c}$ & $7.375 b$ & $7.901 \mathrm{~b}$ & $12.169 \mathrm{a}$ & $11.868 \mathrm{a}$ & 6,76 \\
\hline Produção de feno (kg/ha) & $4.932 \mathrm{c}$ & $6.686 b$ & $6.938 b$ & $10.654 \mathrm{a}$ & $10.850 \mathrm{a}$ & 15,69 \\
\hline $\begin{array}{l}\text { Perdas na fenação (\%) } \\
\text { Haymaking losses }(\%)\end{array}$ & $20,17 \mathrm{a}$ & $17,33 \mathrm{a}$ & $19,70 \mathrm{a}$ & $19,74 \mathrm{a}$ & $17,44 \mathrm{a}$ & 8,15 \\
\hline
\end{tabular}

Médias seguidas de mesma letra, na linha, não diferem $(P<0,05)$ pelo teste Tukey.

Means followed by the same letter in a row do not differ $(P<0.05)$ by Tukey test. 
necessária elevação do teor de MS para viabilizar a utilização de maiores densidades.

As concentrações de PB na MS dos fenos triturados do milheto $(10,56 \%)$, do sorgo sudanense $(8,80 \%)$ e do capim-elefante $(6,76 \%)$ situaram-se acima do mínimo requerido para garantir fermentação ruminal adequada, que, segundo Van Soest (1994), é de 6,25\%. Os menores $(\mathrm{P}<0,05)$ teores de PB foram encontrados para os fenos dos cultivares de sorgo forrageiro, cv. SF- $25(5,62 \%)$ e a cv. IPA467-4-2 (5,50\%). O maior percentual de caules e a idade de corte avançada nos sorgo forrageiros promoveram menores concentrações de PB na planta inteira, determinando a baixa concentração deste constituinte nos fenos. Neumann et al. (2002) registraram diferenças nas concentrações de PB do sorgo forrageiro, com 5,45\% nas folhas e 1,96\% nos colmos

As perdas de $\mathrm{PB}$ registradas no processo de fenação $(\mathrm{MV} \times$ feno) foram, respectivamente, de 13,4; 7,2; 12,2; 29,5 e $20,5 \%$ para o milheto, o sorgo sudanense, o capim-elefante e os sorgos SF-25 e IPA-467-4-2 e provavelmente foram ocasionadas pelo maior tempo para essas culturas atingirem o ponto de feno, aumentando as perdas de compostos nitrogenados em decorrência da reação de Maillard.

As concentrações de FDN obtidas para os fenos foram elevadas e, na sua maioria, apresentaram valores superiores a $70 \%$ (Tabela 3 ). Para o capim-elefante, o teor de FDN de 71,43\% foi inferior aos relatados por Morais et al. (2004) e Pires et al. (2004), de 74,20 e 74,92\%, respectivamente, com fenos da mesma espécie. Os teores de FDN para os fenos dos sorgos $(71,35$ e $73,26 \%)$ estão de acordo com o valor de $72 \%$ relatado por Distel et al. (1994). Para o sorgo sudanense, Galyean \& Defoor (2003) indicaram o teor de $66 \%$ de FDN na MS.

A maior concentração de FDA foi obtida para o feno de capim-elefante $(49,03 \%)$ e diferiu significativamente $(\mathrm{P}<0,05)$ das observadas nos fenos de milheto $(46,05 \%)$ e dos sorgos IPA-467-4-2 (47,27\%) e sudanense (46,37\%), mas situou-se entre os valores relatados por Vilela \& Vilaça (1998) e Silva et al. (1999), de 44,8 e 52,41\%, respectivamente, para fenos da mesma espécie.

As menores concentrações de NIDN foram observadas para o feno dos cultivares de sorgo $(0,42$ e $0,40 \% \mathrm{MS})$, que diferiram dos demais tratamentos $(\mathrm{P}<0,05)$ : capim-elefante $(0,52 \%)$, sorgo sudanense $(0,77 \%)$ e milheto $(0,88 \%)$. A proporção do NIDN/N total variou de 45,45 a $54,66 \%$. Avaliando fenos de capim-elefante anão, Morais et al. (2004) encontraram 50\% do $\mathrm{N}$ total ligado à parede celular, sendo que $70 \%$ desse $\mathrm{N}$ foi digerido. Madibela et al. (2002) relataram valores de NDIN de $0,86 \%$ na MS do sorgo sacarino, que representou $75,7 \%$ do $\mathrm{N}$ total.

Uma variável importante no estudo da degradabilidade da PB dos fenos avaliados é a quantificação do $\mathrm{N}$ associado ao FDN e FDA, assim como a proporção desse $\mathrm{N}$ em relação à $\mathrm{N}$ total e as possíveis relações desses componentes com a digestibilidade e consumo dos nutrientes dessas forragens.

As concentrações de NIDA diferiram significativamente $(\mathrm{P}<0,05)$ entre todos os materiais (variando de 0,06 a 0,30 na MS) e a relação NIDA/N total foi de 3,09 a 15,91\%. A concentração do NIDA para o capim-elefante $(0,22 \%$ MS) e sua relação com o $\mathrm{N}$ total $(10,80 \%)$ são intermediárias entre os valores relatados por Morais et al. (2004) e

Tabela 3 - Valores médios (\% da MS) da composição bromatológica dos fenos triturados das gramíneas forrageiras Table 3 - Chemical composition of tropical grass forage chopped hays (\% of DM)

\begin{tabular}{|c|c|c|c|c|c|c|}
\hline & $\begin{array}{l}\text { Milheto Bulk-1 } \\
\text { Pearl millet Bulk-1 }\end{array}$ & $\begin{array}{c}\text { Sudanense S- } 4202 \\
\text { Sudangrass }\end{array}$ & $\begin{array}{c}\text { Elefante Cameroon } \\
\text { Elephantgrass }\end{array}$ & $\begin{array}{l}\text { Sorgo SF-25 } \\
\text { Sorghum }\end{array}$ & $\begin{array}{c}\text { Sorgo IPA-467-4-2 } \\
\text { Sorghum }\end{array}$ & $\mathrm{CV}(\%)$ \\
\hline $\operatorname{MS}(D M)$ & $90,58 \mathrm{a}$ & $90,33 \mathrm{a}$ & $90,65 \mathrm{a}$ & $90,30 \mathrm{a}$ & $89,28 b$ & 0,51 \\
\hline $\mathrm{PB}(C P)$ & $10,56 \mathrm{a}$ & $8,80 \mathrm{~b}$ & $6,76 \mathrm{c}$ & $5,62 \mathrm{~d}$ & $5,50 \mathrm{~d}$ & 2,31 \\
\hline $\mathrm{EE}$ & $1,43 \mathrm{ab}$ & $1,74 \mathrm{a}$ & $1,47 \mathrm{ab}$ & $1,29 b$ & $1,49 \mathrm{ab}$ & 10,99 \\
\hline $\mathrm{FDN}(N D F)$ & $66,52 \mathrm{c}$ & $69,21 \mathrm{c}$ & $71,43 b$ & $71,35 b$ & $73,26 a$ & 0,74 \\
\hline LIG & $6,52 \mathrm{a}$ & $4,81 \mathrm{c}$ & $5,26 \mathrm{~b}$ & $5,64 b$ & $6,17 \mathrm{a}$ & 3,20 \\
\hline Cinzas (Ash) & $10,53 \mathrm{a}$ & $11,03 \mathrm{a}$ & $10,98 \mathrm{a}$ & $8,77 \mathrm{~b}$ & $8,71 \mathrm{~b}$ & 2,83 \\
\hline $\mathrm{CT}(T C)$ & $74,48 d$ & $78,43 \mathrm{c}$ & $80,78 b$ & $84,33 \mathrm{a}$ & $84,30 \mathrm{a}$ & 0,51 \\
\hline $\mathrm{CNF}(N F C)$ & $10,96 b$ & $9,22 \mathrm{c}$ & $9,35 \mathrm{c}$ & $12,98 \mathrm{a}$ & $11,04 \mathrm{~b}$ & 3,61 \\
\hline CEL & $39,53 \mathrm{c}$ & $41,55 b$ & $43,77 \mathrm{a}$ & $42,88 \mathrm{a}$ & $41,10 \mathrm{~b}$ & 1,07 \\
\hline NIDN (NDIN) & $0,88 \mathrm{a}$ & $0,77 \mathrm{~b}$ & $0,52 \mathrm{c}$ & $0,42 \mathrm{~d}$ & $0,40 \mathrm{~d}$ & 4,71 \\
\hline NIDA $(A D I N)$ & $0,30 \mathrm{a}$ & $0,09 \mathrm{~d}$ & $0,22 b$ & $0,17 \mathrm{c}$ & $0,06 \mathrm{e}$ & 4,40 \\
\hline
\end{tabular}


Kozloski et al. (2001), de 0,16 a 0,34\% na MS e de 10,52 a $15,18 \%$, respectivamente.

$\mathrm{O}$ nitrogênio não-digestível geralmente tem sido estimado a partir do NIDA, mas trabalhos listados por Broderick (1994) indicam que esse componente das forragens é composto por pelo menos duas frações, uma não-digestível e outra de baixa digestibilidade.

As maiores concentrações de lignina na MS dos fenos foram observadas para o milheto $(6,52 \%)$ e para o sorgo IPA-467-4-2 (6,17\%), que não diferiram entre tratamentos ( $\mathrm{P}>0,05)$, mas superaram os teores para os fenos do sorgo SF-25 $(5,64 \%)$, capim-elefante $(5,26 \%)$ e sorgo sudanense $(4,81 \%)$. O teor de lignina do feno de capim-elefante foi inferior ao de $5,71 \%$, relatado em trabalhos com fenos da mesma espécie por Morais et al. (2004). As concentrações de lignina nos fenos de sorgo sudanense e milheto apresentadas por Cherney et al. (1990) foram inferiores às deste trabalho, com valores de 2,35 e 2,55\%, respectivamente.

Lapierre (1993) ressaltou que a lignina é o componente mais negativamente correlacionado à digestibilidade, pois limita a digestão dos polissacarídeos da parede celular e reduz o valor nutricional das plantas para os ruminantes. Segundo Chesson, citado por Moore \& Hatfield (1994), a associação física da lignina aos polissacarídeos da parede celular e a existência de ligações covalentes entre a lignina e esses polissacarídeos são os principais fatores limitantes à acessibilidade desses polissacarídeos como substratos para as enzimas secretadas pelos microrganismos ruminais.

Os teores de cinzas variaram significativamente $(\mathrm{P}<0,05)$ entre os fenos, com valores de 8,71\% no cultivar IPA-467 a $11,03 \%$ para o sorgo sudanense, observando-se os menores valores para os sorgos forrageiros (Tabela 3). Tedeschi et al. (2002) verificaram concentrações de cinzas de $13,0 \%$ no feno de capim-elefante, de $9,1 \%$ em silagens de milheto e de $6,8 \%$ em silagem de sorgo.

Os resultados de NDT estimados nos fenos diferiram significativamente $(\mathrm{P}<0,05)$ entre as espécies, observando-se os valores mais altos para o feno de sorgo sudanense $(53,35 \%)$. Os sorgos forrageiros não diferiram entre si (sorgo
SF-25, 51,79\% e IPA-467-4-2, 51,36\%) e foram superiores ao milheto $(50,30 \%)$ e ao capim-elefante $(50,33 \%)$, que não diferiram. O NRC (1989) sugere concentrações de NDT aproximadas para o feno de sorgo sudanense $(56,0 \%)$ e os fenos e as palhadas de sorgo $(53,0$ a $54,0 \%)$, mas valores superiores para o milheto $(59,0$ a $61,0 \%)$ e o capim-elefante $(54,0 \%)$. O valor do NDT estimado para o feno do capimelefante foi inferior ao relatado por Morais et al. (2004), de $54,8 \%$ para feno da mesma espécie.

Os teores médios dos macrominerais $\mathrm{Ca}, \mathrm{P}, \mathrm{K}, \mathrm{Mg}$ e $\mathrm{S}$ diferiram significativamente $(\mathrm{P}<0,05)$ nos fenos estudados. O feno do milheto apresentou maiores teores de $\mathrm{Ca}$, P e S (Tabela 4) e não diferiu significativamente do capimelefante quanto ao valor de $\mathrm{K}$ e do sorgo sudanens quanto ao teor de $\mathrm{Mg}$.

Os teores de $\mathrm{Ca}$ e $\mathrm{P}$ registrados na $\mathrm{MS}$ dos fenos avaliados oscilaram de 0,20 a $0,37 \%$ e de 0,21 a $0,42 \%$, respectivamente, e foram próximos aos limites para fenos de gramíneas listados pelo NRC (1989) de 0,26 a 0,53\% para o Ca e de 0,19 a 0,27\% para o fósforo. SegundoSpears(1994), as forragens usualmente contêm níveis de $\mathrm{Ca}$ adequados para gado de corte e ovinos, mas a disponibilidade pode ser baixa em função da presença de oxalato de $\mathrm{Ca}$.

O único elemento presente nos cinco fenos em quantidades satisfatórias foi $\mathrm{Mg}(0,13$ a $0,23 \%)$ para os padrões de fenos dessas gramíneas e para atender às exigências dos ruminantes (0,1 a 0,3\%), NRC (1989).

As concentrações de $\mathrm{K}$ foram maiores nas forrageiras que atingiram mais rapidamente o ponto de feno e menores para os cultivares de sorgo, que requereram três dias para atingir o ponto de feno. Reis et al. (2001) destacaram que quebras de folhas e outros processos físicos de fenação podem proporcionar perda de minerais, notadamente de potássio.

Os fenos dos sorgos forrageiros, em relação às demais espécies, apresentaram os menores teores de $\mathrm{S}(\mathrm{P}<0,05)$, o que está de acordo com o observado por Wheeler et al. (1980), que afirmaram que esta espécie apresenta concentrações naturalmente mais baixas desse mineral. De modo geral, mesmo não possuindo arquitetura e morfologia ideais

Tabela 4 - Concentração de macrominerais nos fenos das gramíneas (\%)

Table 4 - Macromineral concentration of forage grass hays (\%)

\begin{tabular}{lccccc}
\hline & $\begin{array}{c}\text { Milheto Bulk-1 } \\
\text { Pearl millet Bulk-1 }\end{array}$ & $\begin{array}{c}\text { Sudanense S-4202 } \\
\text { Sudangrass }\end{array}$ & $\begin{array}{c}\text { Elefante Cameroon } \\
\text { Elephantgrass }\end{array}$ & $\begin{array}{c}\text { Sorgo SF-25 } \\
\text { Sorghum }\end{array}$ & $\begin{array}{c}\text { Sorgo IPA-467-4-2 } \\
\text { Corghum }\end{array}$ \\
\hline $\mathrm{Ca}$ & $0,37 \mathrm{a}$ & $0,27 \mathrm{~b}$ & $0,29 \mathrm{~b}$ & $0,22 \mathrm{c}$ & $0,20 \mathrm{c}$ \\
$\mathrm{P}$ & $0,42 \mathrm{a}$ & $0,33 \mathrm{~b}$ & $0,26 \mathrm{c}$ & $0,21 \mathrm{~d}$ & 7,14 \\
$\mathrm{~K}$ & $3,94 \mathrm{a}$ & $3,06 \mathrm{~b}$ & $4,09 \mathrm{a}$ & $2,55 \mathrm{c}$ & $2,23 \mathrm{~cd}$ \\
$\mathrm{Mg}$ & $0,23 \mathrm{a}$ & $0,22 \mathrm{a}$ & $0,13 \mathrm{c}$ & $0,20 \mathrm{~b}$ & $2,24 \mathrm{~d}$ \\
$\mathrm{~S}$ & $0,26 \mathrm{a}$ & $0,16 \mathrm{~b}$ & $0,17 \mathrm{~b}$ & $0,10 \mathrm{c}$ & 4,36 \\
\hline
\end{tabular}

Médias seguidas de mesma letra na linha não diferem $(P<0,05)$ pelo teste Tukey.

Means followed by the same letter in a row do not differ $(P<0.05)$ by Tukey test. 
para o processo de fenação, as gramíneas avaliadas apresentaram características favoráveis ao processo e um produto final com grande potencial para utilização no semiárido, particularmente na agricultura familiar. Os altos rendimentos, o curto período de desidratação, o valor forrageiro e a facilidade de armazenamento dos fenos triturados permitem considerá-los alternativas estratégicas de reservas de forragens para os períodos de seca.

Estudos adicionais são necessários para avaliar as perdas durante os processos de fenação e armazenamento, os custos de produção e o desempenho de ruminantes.

\section{Conclusões}

A produção de fenos triturados das gramíneas forrageiras tropicais avaliadas apresentou rendimentos satisfatórios, composição químico-bromatológica dentro de padrões recomendáveis para a nutrição de ruminantes e níveis de perdas compatíveis com o processo de fenação.

\section{Literatura Citada}

BEN SALEM, H.; NEFZAOUI, A. Opuntia ssp. - a strategic fodder and efficient tool to combat desertification in the Wana region. In: MONDRAGON-JACOBO, C.; PÉREZ-GONZALÊZ, S.E. (Eds.) Cactus (Opuntia ssp.) as forage. Roma: FAO, 2002. p.73-90.

BRODERICK, G.A. Quantifying forage protein quality. In: FAHEY, G.C. (Ed.) Forage quality, evaluation, and utilization. Madison: American Society Agronomy, 1994. p.200-228.

CAVALCANTI, F.J.A.; SANTOS, J.C.P.; PEREIRA, J.R. et al. Recomendações de adubação para o estado de Pernambuco. 2.ed.rev. Recife: IPA, 1998. 198p.

CHERNEY, D.J.R.; MERTENS, D.R.; MOORE, J.E. Intake and digestibility by wethers as influenced by forage morphology at three levels of forage offering. Journal of Animal Science, v.68, p.4387-4399, 1990 .

DISTEL, R.A.; VILLALBA, J.J.; LABORDE, H.E. Effects of early experience on voluntary intake of low-quality roughage by sheep. Journal of Animal Science, v.79, p.1191-1195, 1994.

FLARESSO, J.A.; GROSS, C.D.; ALMEIDA, E.X. Cultivares de milho (Zea mays L.) e sorgo [Sorghum bicolor (L.) Moench] para ensilagem no Alto Vale do Itajaí, Santa Catarina. Revista Brasileira de Zootecnia, v.29, n.6, p.1608-1615, 2000.

GALYEAN, M.L.; DEFOOR, P.J. Effects of roughage source and level on intake by feedlot cattle. Journal of Animal Science, v.81, p.E8-E16, 2003.

GERALDO, J.; OLIVEIRA, L.D.; PEREIRA, M.B. et al. Fenologia e produção de massa seca e de grãos em cultivares de milhetopérola. Pesquisa Agropecuária Brasileira, v.37, n.9, p.2093-2098, 2002.

GONTIJO NETO, M.M.; OBEID, J.A.; PEREIRA, O.G. et al. Híbridos de sorgo (Sorghum bicolor (L.) Moench) cultivados sob níveis crescentes de adubação. Rendimento, proteína bruta e digestibilidade in vitro. Revista Brasileira de Zootecnia, v.31, n.4, p.1640-1647, 2002.

HADDAD, C.M.; DOMINGUES, J.L. [2005] O que avaliar para comprar feno de qualidade? Disponível em: <http:// www.endurancebrasil.com.br/port/tecnicas/feno.php> Acesso em: $15 / 04 / 2005$
INSTITUTO NACIONAL DE METEOROLOGIA - INMET. Mapa de observações meteorológicas mensais . Cruzeta: 2002. 12 p.

KOZLOSKI, G.V.; PEROTTONI, J.; CIOCCA, M.L.S. et al. Avaliação do potencial nutricional do feno de capim-elefante anão (Pennisetum purpureum Schum. cv. Mott). 1. Composição química e digestibilidade. In: REUNIÃO ANUAL DA SOCIEDADE BRASILEIRA DE ZOOTECNIA, 38., 2001, Piracicaba. Anais... Piracicaba: Sociedade Brasileira de Zootecnia, 2001. (CD-ROM)

LAPIERRE, C. Application of new methods for the investigation of lignin structure. In: JUNG, H.G.; BUXTON, D.R.; HATFIELD, R.D. et al. (Eds.). Forage cell wall structure and digestibility Madison: American Society Agronomy, 1993. p.133-166.

LICITRA, G.; HERNANDEZ, T.M.; Van SOEST, P.J. Standardization of procedures for nitrogen fractionation of ruminant feeds. Animal Feed Science and Technology, v.57, p.347-358, 1996.

LIMA, G.F.C.; MACIEL, F.C. Fenação e ensilagem: Estratégias de armazenamento de forragens no Nordeste. In: SIMPÓSIO NORDESTINO DE ALIMENTAÇÃO DE RUMINANTES, 6. 1996, Natal. Anais... Natal: UFRN/EMPARN, 1996. p.3-31.

LIMA, G.F.C. Alternativas de seleção e manejo de volumosos forrageiros para a atividade leiteira do Nordeste. In: O AGRONEGÓCIO DO LEITE NO NORDESTE: ALTERNATIVAS TECNOLÓGICAS E PERSPECTIVAS DE MERCADO, 1998, Natal. Anais... Natal: EMPARN/FIERN/ SENAI, 1998. p.190-226.

LIMA, G.F.C.; AGUIAR, E.M.; PEREIRA, A.V. Avaliação de clones de capim-elefante para capineiras no Rio Grande do Norte. In; REUNIÃO ANUAL DA SOCIEDADE BRASILEIRA DE ZOOTECNIA, 40., 2003, Santa Maria. Anais... Santa Maria: Sociedade Brasileira de Zootecnia, 2003 (CD-ROM).

MADIBELA, O.R.; BOITUMELO, W.S.; MANTHE, C. et al. Chemical composition and in vitro dry matter digestibility of local ladraces of sweet sorghum in Botswana. Livestock Research for Rural Development, v.14, n.4, p.1-6, 2002.

MALAVOLTA, E. Avaliação do estado nutricional das plantas: princípios e aplicações. 2.ed.rev. Piracicaba: Associação Brasileira para Pesquisa da Potassa e do Fósforo - POTAFOS, 1997. 319p.

MOORE, K.J.; HATFIELD, R.D. Carbohydrates and forage quality. In: FAHEY, G.C. (Ed.) Forage quality, evaluation, and utilization. Madison: American Society Agronomy, 1994. p.229-280.

MORAIS, J.A.S.; KOZLOSKI, G.V.; REFFATTI, M.V. et al. Nível de consumo e sua relação com o valor nutritivo do feno de capim-elefante anão (Pennisetum purpureum Schum. cv. Mott) oferecido a ovinos. In: REUNIÃO ANUAL DA SOCIEDADE BRASILEIRA DE ZOOTECNIA, 41., 2004, Campo Grande. Anais... Campo Grande: Sociedade Brasileira de Zootecnia, 2003. (CD-ROM)

NATIONAL RESEARCH COUNCIL - NRC. Nutrient requirements of dairy cattle. 6.rev.ed. Washington, D.C.: National Academy Press, 1989. 242p.

NATIONAL RESEARCH COUNCIL - NRC. Nutrient requirements of dairy cattle. 7.ed. Washington, D.C.: National Academy Press, 2001. 336p.

NEUMANN, M.; RESTLE, J.; ALVES FILHO, D.C. et al. Avaliação do valor nutritivo da planta e da silagem de diferentes híbridos de sorgo (Sorghum bicolor, L. Moench). Revista Brasileira de Zootecnia, v.31, n.1, p.293-301, 2002.

NOBRE, F.V. Fenação: uma maneira inteligente para melhorar a alimentação dos rebanhos nordestinos. Natal: EMATER-RN, 1987. 33p.

NOBRE, F.V.; NOBRE, J.M.; MOREIRA, C.G. et al. Diagnóstico da bovinocultura leiteira do Rio Grande do Norte. In: SIMPÓSIO O AGONEGÓCIO DO LEITE NO NORDESTE: ALTERNATIVAS TECNOLÓGICAS E PERSPECTIVAS DE MERCADO, 1998 , Natal. Anais... Natal: 1998. p.121-140. 
PINTO, J.C.; MAIA, M.C.; SANTOS, P.A. et al. Composição mineral da forragem do milheto e do Tanzânia cultivados associados. In: REUNIÃO ANUAL DA SOCIEDADE BRASILEIRA DE ZOOTECNIA, 39., 2002, Recife. Anais... Recife: Sociedade Brasileira de Zootecnia, 2002. (CD-ROM)

REIS, R.A.; MOREIRA, A.L.; PEDREIRA, M.S. Técnicas para produção e conservação de fenos de forrageiras de alta qualidade. In: SIMPÓSIO SOBRE PRODUÇÃO E UTILIZAÇÃO DE FORRAGENS CONSERVADAS, 1., 2001, Maringá. Anais... Maringá: Universidade Estadual de Maringá, 2001. p.1-39.

PIRES, A.J.V.; CARVALHO, G.G.P.; VELOSO, C.M. et al. Degradabilidade in situ do feno de alguns alimentos volumosos empregados na alimentação de ruminantes. In: REUNIÃO ANUAL DA SOCIEDADE BRASILEIRA DE ZOOTECNIA, 41. 2004, Campo Grande. Anais... Campo Grande: Sociedade Brasileira de Zootecnia, 2004. (CD-ROM)

ROTZ, C.A.; MUCK, R.E. Changes in forages quality during harvest and storage. In: FAHEY, G.C. (Ed.) Forage quality, evaluation, and utilization. Madison: American Society Agronomy, 1994. p.828-868.

SANTOS, F.A.P.; MARTINEZ, J.C.; VOLTOLINI, T.V. et al. Associação de plantas forrageiras de clima temperado e tropical em sistemas de produção animal de regiões subtropicais. In: SIMPÓSIO SOBRE MANEJO DA PASTAGEM, 20., 2003, Piracicaba. Anais... Piracicaba: Fundação de Estudos Agrários Luz de Queiroz, 2003. p.215-246.

STASTICAL ANALYSIS SYSTEMS - SAS. User's guide. version 6, 4.ed. Cary: 1995, v.2.

SILVA, D.J.; QUEIROZ, A.C. Análises de alimentos (métodos químicas e biológicos). Viçosa, MG: Universidade Federal de Viçosa, 2002. p.253.

SILVA, J.H.V.; RODRIGUES, M.T; CAMPOS, J. Influência da seleção sobre a qualidade da dieta ingerida por caprinos com feno oferecido em excesso. Revista Brasileira de Zootecnia, v.28, n.6, p.1419-1423, 1999.

SILVA, S.C.; CORSI, M. Manejo do pastejo. In: SIMPÓSIO SOBRE MANEJO DE PASTAGEM, 20., 2003, Piracicaba. Anais... Piracicaba: Fundação de Estudos Agrários Luiz de Queiroz, 2003. p.155-185.
SNIFFEN, C.J.; O'CONNOR, J.D.; Van SOEST, P.J. A net carbohydrate and protein system for evaluation cattle diets. II. Carbohydrate and protein availability. Journal of Animal Science, v.70, n.11, p.3562-3577, 1992.

SPEARS, J.W. Minerals in Forages. In: FAHEY, G.C. (Ed.) Forage quality, evaluation, and utilization. Madison: American Society Agronomy, 1994. p.281-317.

STAPLER, C.R. [2003] Microwave drying for measurement for forage moisture. Florida: University of Florida, Institute of Food and Agricultural Science. Disponível em: <http:// edis.ifas.edu/DS156\#FOOTNOT_1>. Acesso em: 30/11/04.

TEDESCHI, L.O.; FOX, D.G.; PELL, A.N. et al. Development and evaluation of a tropical feed library for the Cornell net carbohydrate and protein system model. Scientia Agricola, v.59, n.1, p.1-18, 2002.

Van SOEST, P.J.; ROBERTSON, J.B.; LEWIS, B.A. Methods for dietary fiber neutral detergent and nonstarch polysaccharides in relation to animal nutrition. Journal of Dairy Science, v.74, n.10, p.3583-3597, 1991.

Van SOEST, P.J. Nutritional ecology of the ruminant. 2.ed. New York: Cornell University Press, 1994. 476p.

VILELA, D.; VILLAÇA, H.A. Feno de capim-elefante (Pennisetum purpureum Schum.) preparado por diferentes métodos e sua utilização por animais em crescimento. Revista Brasileira de Zootecnia, v.27, n.3, p.481-486, 1998.

WHEELER, J.L.; HEDGES, D.A.; ARCHER, K.A. Effect of nitrogen, sulfur and phosphorus fertilizer on the production, mineral content and cyanide potential of forage sorghum. Australian Journal of Experimental Agriculture and Animal Husbandry, v.20, p.330-338, 1980. 